\title{
Keterkaitan Manajemen Pengetahuan dan Kecakapan Organisasional dengan Kinerja Inovasi serta Fungsi Mediasi Orientasi Kewirausahaan
}

\author{
Any Rustia Dewi ${ }^{(1)} \&$ Suatmo Pantja Putra ${ }^{(2)}$ \\ Fakultas Ekonomi \& Bisnis, Universitas Merdeka Malang \\ Email: ${ }^{1}$ anyrustia@gmail.com
}

\section{Tersedia Online di \\ http://www.jurnal.unublitar.ac.id/ index.php/briliant \\ Sejarah Artikel \\ Diterima pada 16 Juni 2017 \\ Disetuji pada 30 Juni 2017 \\ Dipublikasikan pada: 2 Agustus 2017 Hal 281-293}

\section{Kata Kunci: \\ manajemen pengetahuan, kinerja inovasi, kewirausahaan}

\begin{abstract}
Abstrak: Penelitian ini bertujuan untuk memperkaya khasanah keilmuan manajemen dalam konteks kinerja inovasi. Penelitian ini adalah penelitian penjelasan dengan metode kuantitatif. Teknik pengambilan data yang digunakan adalah teknik sampel proporsional dengan jumlah responden 100 UKM sebagai syarat minimal dalam analisis Structural Equation Model (SEM). Sedangkan teknis data yang digunakan adalah Structural Equation Model (SEM) Analysis. Hasil penelitian menunjukkan bahwa terdapat keterkaitan antara manajemen pengetahuan dan kecakapan organisasional dengan kinerja inovasi yang dimediasi oleh orientasi kewirausahaan. Maknanya, untuk meningkatkan kinerja inovasi dibutuhkan manajemen pengetahuan dan kecakapan organisasi sekaligus sikap orientasi kewirausahaan.
\end{abstract}

Inovate or die. Ungkapan yang sangat populer pada era perubahan akhirakhir ini. Hal itu karena pasar makin kompetitif. Lebih-lebih pada akan berlangsungnya era ASEAN Economics Community (AEC) yang dimulai akhir tahun 2015 ini. Konsekwensinya, entitas bisnis mutlak berinovasi guna membangun daya saingnya, yang secara umum dapat dilakukan melalui inovasi produk dan proses (Popadiuk \& Choo, 2014).

Yang menarik, perdebatan faktor yang mempengaruhi kinerja inovasi terus berkembang sejalan dengan dinamika temuan hasil riset. Hal tersebut terungkap dari beberapa periset menyatakan bahwa pengalaman kerja, keterampilan, motivasi dan manajemen pengetahuan sebagai key factors terhadap kinerja inovasi (Setyani et all.,2013 Karaveg, 2013; Li \& Zeng, 2014; Abdi \& Amatsewnin (2015).

Sementara, Stetler \& Magnusson (2014) menjelaskan bahwa inovasi dalam organisasi dapat berhasil manakala menggunakan serangkaian standar tindakan atau sistem seperti merancang gagasan, evaluasi dan upaya manajerial yang bersifat fleksibel. Ditegaskan pula, pendekatan tersebut membantu dan mendorong seseorang bukan hanya berpartisipasi dalam kegiatan inovasi dilingkungan tempat kerjanya, tetapi juga menjadi bagian dari merancang kegiatan inovasi organisasi.

Crossan \& Apaydin (2013) menekankan pada sifat dualistik inovasi antara eksplorasi dan eksploitasi, individu dan kolektif, STI (Sains, Teknologi dan Inovasi) dan MMI (Melakukan, Menggunakan dan Interaksi). Selain itu, Karaveg (2013); Rodriguez et. all (2014) dan Abdi \& Amatsenwin (2014) 
mengungkapkan bahwa akselator utama munculnya inovasi organisasi didorong oleh kecakapan organisasional. Periset lain, Basile (2013) mengungkapkan bahwa orientasi kewirausahaan sebagai faktor utama pada kinerja inovasi.

Kemudian, Ullah et. all (2016) menyatakan bahwa entreprise optimalisation merupakan faktor penentu kinerja inovasi. Temuan lain yang cukup berbeda, Yaqoubi \& Narroui (2016) menegaskan bahwa kecakapan organisasionallah yang dapat mempengaruhi orietasi kewirausahaan sekaligus kinerja inovasi organisasi. Sehingga berdasarkan paradoks permasalahan hasilhasil riset tersebut, peneliti bermaksud melakukan penelitian untuk kepentingan klarifikasi empiris terhadap perdebatan tersebut. Sementara, penggunaan obyek riset usaha kecil menengah (UKM), karena entitas bisnis ini menghadapi banyak persoalan yang tak kunjung tuntas. Tujuan dari kegiatan penelitian "Keterkaitan Manajemen Pengetahuan dan Kecakapan Organisasional dengan Kinerja Inovasi serta Fungsi Mediasi Orientasi Kewirausahaan" ini, adalah (a) untuk menganalisis signifikansi pengaruh manajemen pengetahuan terhadap orientasi kewirausahaan, (b) untuk menganalisis signifikansi pengaruh kecakapan organisasional terhadap orientasi kewirausahaan (c) untuk menganalisis signifikansi pengaruh orientasi kewirausahaan terhadap kinerja inovasi, (d) untuk menganalisis fungsi mediasi orientasi kewirausahaan pada pengaruh manajemen pengetahuan dan kecakapan organisasional terhadap kinerja inovasi.

Woodman (2014) mengungkapkan bahwa kinerja inovasi adalah sebuah kinerja yang diukur dari tiga dimensi, yang meliputi inovasi produk, inovasi proses dan inovasi manajerial, yang berimplikasi pada peningkatan kualitas dan efisiensi. Pada dasarnya, inovasi dilakukan dengan pengembangan produk, layanan dan metode yang baru untuk organisasi dan dilakukan untuk kepentingan organisasi. Kemudian, Crossan and Apaydin (2010) menyatakan bahwa kinerja inovasi adalah penciptaan atau penerimaan, adaptasi dan pemanfaatan nilai-nilai kebaruan. Hal itu dapat dilakukan melalui regenerasi dan perluasan produk, layanan dan pasar, membuat cara-cara baru pengembangan produk dan membangun sistem manajemen baru. Selanjutnya, Orlikowski (2010) menyatakan bahwa inovasi adalah proses pengembangan luaran baru dengan mengadopsi cara-cara baru dalam bekerja, termasuk pengembangan produk.

Selain itu, inovasi juga dikaitkan dengan peningkatan kinerja yang lebih baik dengan memproduksi layanan baru, proses dan produk. Inovasi dianggap pembaharuan generatif dan kompetensi organisasi untuk beradaptasi dengan lingkungan. Namun inovasi dianggap sebagai masalah setiap hari bagi anggota organisasi dalam mendefinisikan masalah, menanggapi kejadian tak terduga, penciptaan solusi dan pengembangan cara dan prosedur baru untuk mengatur pekerjaan, melalui penggunaan pengalaman, keterampilan, motivasi dan pengetahuan. Kocher (2011), Miettinen et al (2009) menjelaskan bahwa praktik inovasi organisasi diselenggarakan, didirikan dengan menggunakan serangkaian standar tindakan atau sistem seperti merancang sebuah ide atau pemikiran, evaluasi dan upaya manajerial untuk inovasi seperti peran yang fleksibel, rotasi, untuk mengorganisir kelompok. Sedangkan Woodman (2008) menyatakan bahwa kinerja inovasi dipandang sebagai kenaikan dalam pekerjaan sehari-hari anggota organisasi dan tingkat eksplorasi individu.

Selanjutnya, Pearce, Fritz, \& Davis (2014) mengungkapkan bahwa kewirausahaan diakui sebagai sumber penting pertumbuhan pekerjaan dan 
pembangunan ekonomi suatu negara. Laju pertumbuhan kewirausahaan bervariasi dari satu negara ke negara serta dari waktu ke waktu untuk negara yang sama. Tapi fakta yang dibentuk bahwa hal itu memiliki dampak yang jelas dan positif terhadap pertumbuhan ekonomi. Pengusaha adalah kekuatan pendorong di belakang perkembangan ekonomi negara-negara. Dalam Schumpeter dinyatakan, kerangka bukanlah fenomena yang harmonis melainkan gangguan status quo, membuat pengusaha menjadi heroik. Oleh karena itu, pengusaha dalam konteks Schumpeter adalah inovator yang mampu melakukan kombinasi baru yang menyebabkan sebuah evolusi ekonomi.

Basile (2015) mengungkapkan tentang makna orientasi kewirausahaan sebagai instrumen potensial untuk organisasi menyegarkan, dimana dapat dicapai melalui inovasi, berani mengambil risiko, dan proaktif. Dalam literatur lain, ada kesepakatan tentang tiga dimensi orientasi kewirausahaan yang ternyata berhubungan positif dengan kinerja. Banyak juga yang menambahkan dua dimensi lainnya seperti agresivitas dan otonomi. Namun, inovasi pertama kali ditunjukkan oleh Schumpeter (1942) sebagai dimensi penting dalam proses kewirausahaan. Hal ini terkait dengan proses kreatif, pengembangan ide-ide baru, dan kebaruan. Selain itu, inovasi juga sebagai penggerak keuntungan. Karena itu, orientasi kewirausahaan berkaitan erat dengan kemampuan manajemen. untuk mempromosikan dan mendukung pertimbangan kreativitas, fleksibilitas dan resiko.

Juga, Zaied, Hussein \& Hassan (2016) memaknai manajemen pengetahuan sebagai sebuah proses yang membantu organisasi untuk menemukan, memilih, mengatur, menyebarkan, dan mentransfer informasi penting dan keahlian yang diperlukan untuk kegiatan. Terdapat empat proses dalam manajemen pengetahuan, yaitu: akuisisi pengetahuan, konversi pengetahuan, aplikasi pengetahuan, dan perlindungan pengetahuan. Dijelaskan lebih lanjut bahwa manajemen pengetahun dapat mendorong inovasi, yang kemudian berpotensi meningkatkan daya saing. Dijelaskan juga,manajemen pengetahuan terdiri atastacit dan explicit knowledge. Pada dasarnya tacit knowledge bersifat personal. Berdasarkan pengertiannya, tacit knowledge dikategorikan sebagai personal knowledge atau dengan kata lain pengetahuan yang diperoleh dari individu. Menurut Khan (2012), penelitian pada sifat dasar pengetahuan seketika mempertemukan perbedaan antara knower dan known, atau seringkali diartikan dalam istilah subject dan object, atau ingredient subjective dan objective dalam pengalaman. Pengalaman yang diperoleh tiap orang berbeda-beda. Kemudian, explicit knowledge bersifat formal dan sistematis yang mudah untuk dikomunikasikan dan dibagi. Penerapan explicit knowledge ini lebih mudah karena pengetahuan yang diperoleh dalam bentuk tulisan atau pernyataan yang didokumentasikan, sehingga setiap karyawan dapat mempelajarinya secara independen.

Pada sisi lain, Gholami (2012) memaknai kecakapan organisasional sebagai kemampuan untuk melakukan akuisisi dan analisis informasi untuk meningkatkan pengetahuan dan kesadaran menyediakan informasi yang dibutuhkan untuk harmonisasi organisasi. Meskipun masih terdapat banyak pertanyaan tentang kecerdasan organisasional, faktor-faktor yang mempengaruhi dan kaitannya dengan kinerja manajer. Kecakapan organisasional sangat berbeda antara setiap sumberdaya manusia. Ini berarti bahwa serangkaian faktor 
eksternal dan internal mempengaruhi kecakapan tersebut. Beberapa organisasi kerap berjalan statis, karena tidak dapat mengenali sinyal yang kuat dari perubahan sekitar dan tidak dapat menanggapi stimulan tersebut. Organisasiorganisasi seperti ini harus belajar perlahan dan tidak mengulangi kesalahannya. Filosofi keberadaan organisasi tergantung pada kehidupan manusia. Manusia mendorong semangat dalam organisasi untuk tubuh, memindahkannya dan mengelolanya. Oleh karena itu, sumber daya manusia merupakan unsur yang paling berharga bagi organisasi. Hal itu karena dapat meumuskan keputusan organisasi dan menawarkan solusi dan akhirnya memecahkan berbagai masalah masalah. Formatnya berwujud produktivitas dan memberikan kontribusi pada efisiensi dan efektivitas. Kecakapan berorganisasi membantu untuk mengenali titik lemah organisasi dan untuk memperkuat poin positif.

Banyak riset terdahulu mengungkapkan bahwa orientasi kewirausahaan berpengaruh nyata terhadap kinerja inovasi. Salah satunya terungkap dari hasil riset Lisboa dan Skarmeas (2010) pada penelitiannya yang berjudul Entrepreneurial orientation, innovative capabilities, and performance outcomes: An empirical investigation, bahwa orientasi kewirausahaan memiliki pengaruh signifikat terhadap inovasi. Peneliti lain, Madhoushi, et all (2011), pada risetnya Entrepreneurial Orientation and Innovation Performance: The Mediating Role of Knowledge Managemen" mengungkapkan bahwa orientasi kewirausahaan berpengaruh terhadap kinerja inovasi organisasi. Yang terbaru, Al-Dhaafri dan Al-Swidi (2014) pada artikelnya The Entrepreneurial Orientation and The organizational Performance: Does Enterprise Resource Planning Have A Mediating Role: A Study on Dubai Police menegaskan bahwa inovasi sebagai salah satu indikator kinerja organisasi berkaitan erat dengan orientasi kewirausahaan. Yang terbaru, Wang et all, (2015), pada artikelnya Entrepereneural Orientation and Organizational Learning on SME Innovation Menegaskan juga bahwa orientasi kewirausahaan berpengaruh terhadap kinerja inovasi. Keterkaitan kecakapan organisasional dengan orientasi kewirausahaan dan kinerja inovasi terungkap pada hasil beberapa periset diantaranya adalah Gholami (2015) pada artikelnya The Realtionship Between The Organizational Intelegence and The Performance of Managers menjelaskan bahwa kecakapan organisasional berpengaruh positif terhadap kinerja manajer dan salah satu indikatornya adalah inovasi. Kemudian, Ahmadi \& Ranbari, 2013) pada artikelnya Organizational Intelligence effect on entrepreneurship improvement ( $A$ case study research), menyatakan bahwa intelejensi organisasi berpengaruh signifikan terhadan orientasi kewirausahaan. Juga, Nasabee, Jahanee \& Safarpour (2013) dalam artikel risetnya Relationship of Organizational Intelligence and Personal Creativity in Shiraz University of Medical Science menyatakan terdapat hubungan searah dan signifikan antara kecakapan organisasional dengan kinerja inovasi. Bahkan dalam riset terbaru yang dilakukan Bakhsian, Hamidi \& Ezati, 2014) mengungkapkan bahwa kecakapan organisasional mempunyai pengaruh terhadap orientasi kewirausahaan. Hubungan antara manajemen pengetahuan dengan orientasi kewirausahaan dan inovasi institucional dinyatakan oleh beberapa peneliti diantaranya adalah Price, Stoica \& Boncella (2013) pada artikel hasil risetnya The relationship between innovation, knowledge and performance infamily and non-family firms: Ananalysis of SMEs 
mengungkapkan bahwa terdapat hubungan antara manajemen pengetahuan dan inovasi pada industri kecil menengah. Riset lain yang dilakukan oleh Rodríguez et all (2013) yang berjudul Knowledge Management and the Effectiveness of Innovation Outcomes: The Role of Cultural Barriers mendapatkan bahwa manajemen pengetahuan berpengaruh nyata terhadap inovasi melalui variabel antara budaya.

Selanjutnya, Githii (2014) dalam artikelnya Knowledge management practices and innovation performance: a literature review mengungkapkan bahwa manajemen pengetahuan mempunyai dampak pada inovasi dalam sebuah organisasi. Kemudian fakta empiris keterkaitan transdisiplinaritas dengan orientasi kewirausahaan dan inovasi institucional dinyatakan oleh beberapa peneliti diantaranya adalah Srivasthava dan Ivanaj (2011) dalam artikelnya Transdisciplinary Art, Technology, and Management for Sustainable Enterprise mengungkapkan bahwa transdiplinaritas berdampak positip pada orientasi kewirausahaan. Juga, Gangi (2014) Arts Entrepreneurship: An Essential SubSystem of the Artist's Meta-Praxis menyatakan bahwa trandisiplinaritas mempunyai hubungan kuat dengan orientasi kewirausahaan. Mittelmark et all (2012), pada tulisan ilmiahnya Computeeer Mediated Communication in Alice Rap: Method to Enhance The Quality of Large Scale Trandciplinarity Research menjelaskan bahwa trandisiplinaritas mempunyai hubungan searah dengan pencapaian kinerja inovasi. Selanjutnya, Porter (2014) dalam artikelnya $A$ Transdisciplinary Model to Improve Screening and Early Intervention within Dietetics and Speech Pathology: A Case Study mengungkapkan bahwa transdisiplinaritas berpengaruh signifikan tehadap kinerja inovasi.

Berdasarkan beberapa penelitian terdahulu, maka hipotesis penelitiannya adalah (a) Manajemen pengetahuan berpengaruh signifikan terhadap orientasi kewirausahaan, (b) Kecakapan organisasional bepengaruh signifikan terhadap orientasi kewirausahaan, (c) Manajemen pengetahuan berpengaruh signifikan terhadap kinerja inovasi, (d) Kecakapan organisasional berpengaruh signifikan terhadap kinerja inovasi, (e) Orientasi kewirausahaan berpengaruh signifikan terhadap kinerja inovasi dan (f) Kecakapan organisasional dan manajemen pengetahuan berpengaruh tidak langsung melalui orientasi kewirausahaan terhadap kinerja inovasi.

\section{METODE}

Kegiatan penelitian ini adalah penelitian penjelasan dengan metode kuantitatif. Pengumpulan data dengan teknik survei, suatu kajian yang mengambil sampel dari satu populasi dengan menggunakan kuesioner sebagai alat pengumpul data pokok. Unit analisisnya, semua pelaku UKM di Kota Batu. Dari sifat pembentukannya ada dua variabel yang dikaji, yaitu: variable laten dan variabel manifes. Variabel laten (variabel konstruk, variabel bentukan dan variabel tak teramati) adalah variabel yang dibentuk dari variabel-variabel indikator, sedangkan variabel manifes (variabel terukur, variabel teramati, variabel indikator) adalah variabel yang datanya harus dicari di lapangan, yang diperoleh melalui kuesioner. Dari sifat hubungannya dengan variabel lain, terdiri dari variabel eksogen dan variabel endogen. Variabel eksogen adalah variabel yang variasinya mempengaruhi variabel lain, sedangkan variabel endogen adalah variabel yang variasinya dipengaruhi variabel lain. Pada kegiatan penelitian ini,

285 BRILIANT: Jurnal Riset dan Konseptual Volume 2 Nomor 3, Agustus 2017 
variabel manajemen pengetahuan dan kecakapan organisasional sebagai variabel eksogen, orientasi kewirausahaan sebagai variabel mediasi dan kinerja inovasi sebagai variabel endogen.

Populasi pada penelitian ini adalah semua pelaku IKM di Kota Batu yang berjumlah 6.050 unit UKM (Dinas Koperasi, Industri dan Perdagangan Kota Batu, 2015). Mengingat jumlah responden yang relatif besar dan untuk mengantisipasi adanya data yang cacat, maka teknik pengumpulan data yang digunakan adalah proportional random sampling yaitu sebuah satuan sampel yang dipilih berdasarkan pertimbangan proporsi tertentu dengan tujuan untuk

mendapatkan sampel dengan karakteristik tertentu, dengan kuota sampel sebanyak 100 responden. Menurut Sugiyono (2009), mengenai responden yang representatif dengan menggunakan teknik analisis SEM adalah 100-200 orang responden atau 5 kali indikator ( $>85$ responden). Karenanya, jumlah responden pada penelitian ini ditentukan 100 responden pelaku IKM dengan pasar minimal Jawa Timur.

Kemudian, pada penelitian ini, data yang dikumpulkan menggunakan daftar pertanyaan atau kuesioner. Kuesioner merupakan cara pengumpulan data dengan memberikan daftar pertanyaan kepada responden untuk diisi. Pertanyaanpertanyaan yang terdapat di dalam kuesioner dibuat dalam bentuk pertanyaan dengan menggunakan skala 1-5 dari tidak setuju sampai sangat setuju. Tentu, instrumen penelitiannya yang sudah teruji validitas dan reliabilitasya.

Teknik analisis data yang digunakan adalah Structual Equation Model (SEM) sebagaimana pendapat Ferdinand (2013), secara bertahap akan menggunakan dua macam teknik analisis (a) Factor Analysis pada SEM, digunakan untuk mengkonfirmasikan faktor-faktor yang paling dominan dalam satu kelompok variabel, (b) Regression Weight pada SEM, digunakan untuk confirmatory meneliti seberapa besar hubungan antar variabel.

\section{HASIL}

Berdasarkan hasil analisis data dengan menggunakan teknik analisis structural equation equation model, didapat path diagram adalah sebagai berikut.

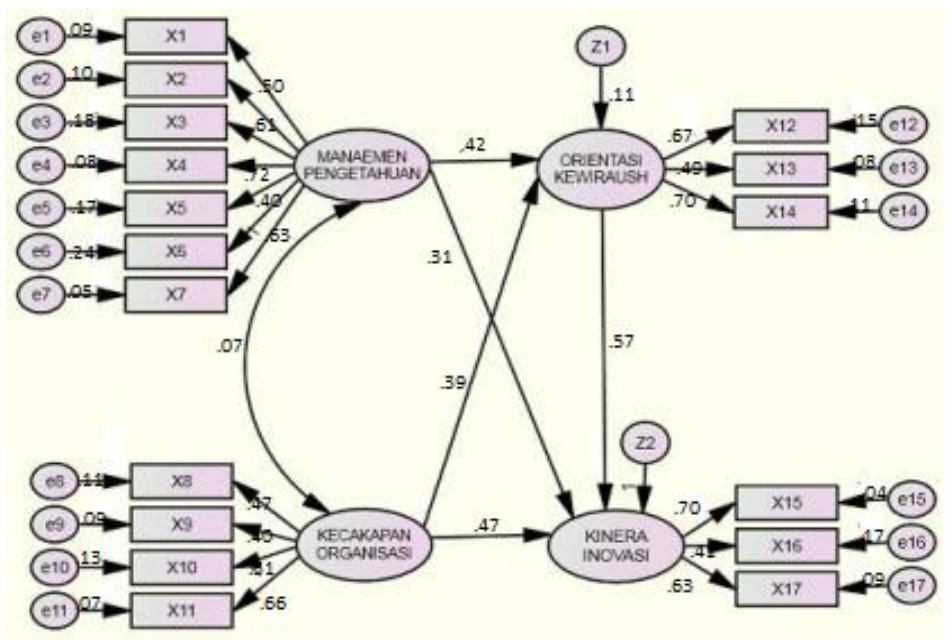

Gambar 1. Keterkaitan keterkaitan manajemen pengetahuan dan kecakapan organisasional dengan kinerja inovasi serta fungsi mediasi orientasi kewirausahaan. 
Berdasarkan gambar 1 tersebut terungkap tedapat pengaruh positip antara variabel antara variabel penelitian. Manajemen pengetahuan berpengaruh terhadap orientasi kewirausahaan (0.42) dan juga berpengaruh terhadap kinerja inovasi (0.31). Kecakapan organisasi berpengaruh terhadap orientasi kewirausahaan (0.39) dan juga berpengaruh terhadap kinerja inovasi (047). Terakhir, orientasi kewirausahaan berpengaruh terhadap kinerja inovasi (0.57)

Sedangkan uji kelayakan model hubungan ketiga variabel penelitian tersebut dijelaskan pada tabel Goodness of Fit Index pada tabel 1, adalah sebagai berikut:

Tabel 1 Goodness of Fit Index Keterkaitan Manajemen Pengetahuan, Orientasi Kewirausahaan, Kecakapan Organisasi dan Kinerja Inovasi.

\begin{tabular}{|l|l|l|l|}
\hline Goodness of Fit Index & Cut-off Value & Hasil Analisis & Evaluasi Model \\
\hline $\mathrm{X}^{2}$ - Chi-square & $\begin{array}{l}\mathrm{P}=5 \%, \quad \text { Chi- } \\
\text { Square 68.673 }\end{array}$ & 39.022 & Baik \\
\hline $\begin{array}{l}\text { Signifinacance } \\
\text { Probability }\end{array}$ & $\geq 0.05$ & 0.071 & Baik \\
\hline RMSEA & $\leq 0.08$ & 0.009 & Marginal \\
\hline GFI & $\geq 0.90$ & 0.999 & Baik \\
\hline AGFI & $\geq 0.90$ & 0.971 & Baik \\
\hline CMIN/DF & $\leq 2.00$ & 1.770 & Baik \\
\hline TLI & $\geq 0.95$ & 0.983 & Baik \\
\hline CFI & $\geq 0.95$ & 0.957 & Baik \\
\hline
\end{tabular}

Sumber data pimer diolah, 2016

Dari Tabel 1, dapat dilihat dari tingkat signifikansi sebesar 0,071 menunjukkan bahwa hipotesis nol yang menyatakan bahwa tidak ada perbedaan antara matrik kovarians sample dengan matriks kovarians populasi yang diestimasi tidak dapat ditolak. Indeks-indeks lainnya ternyata juga menunjukkan tingkat penerimaan yang baik.

Oleh karena itu model ini dapat diterima sehingga dapat dinyatakan bahwa terdapat dua kontruk yang berbeda dengan dimensi-dimensinya. Indeksindeks kesesuaian model lainnya seperti RMSEA (0,009); GFI $(0,999)$; AGFI (0,971); CMIN/DF (1,770); TLI (0,983) dan CFI (0,957) memberikan konfirmatori yang cukup untuk dapat diterimanya hipotesis unidimensionalitas bahwa ketiga variabel diatas dapat mencerminkan variabel laten yang dianalisis.

Selanjutnya, uji dilakukan untuk mengetahui apakah sebuah variabel dapat digunakan untuk mengkonfirmasi bahwa variabel itu dapat bersama-sama dengan variabel lainnya menjelaskan sebuah variabel laten yang dikaji dengan menggunakan tahapan analisis sebagai berikut ini :

\section{Nilai Lambda atau Factor Loading}

Nilai Lambda yang dipersyaratkan adalah harus mencapai lebih besar atau sama dengan 0,40 . bila nilai lambda atau faktor loading lebih rendah dari 0,40 maka dipandang bahwa variabel itu tidak berdimensi sama dengan variabel lainnya untuk menjelaskan sebuah variabel laten. Dengan demikian maka dapat 
disimpulkan bahwa variabel-variabel tersebut secara bersama-sama menyajikan undimensionalitas untuk variabel laten.

\section{Bobot Faktor (Regression Weight)}

Analisis ini dilakukan untuk mengetahui bagaimana kuatnya dimensidimensi itu membentuk factor laten-nya dengan menggunakan uji terhadap regression weight yang dihasilkan oleh model. Dilihat dari hasil ini maka tiaptiap indikator dari masing-masing variabel laten sudah memenuhi syarat sehingga dapat diterima, karena mempunyai nilai loading factor (Koefisien $\lambda$ ) atau regression weight atau standardized estimate yang signifikan dengan nilai Critical Ratio (CR) diatas atau sama dengan 2,0.

Dari hasil ini dapat dilihat bahwa setiap indikator-indikator dari masingmasing dimensi memiliki nilai loading factor (koefisien $\lambda$ ) atau regression weight atau standardized estimate yang signifikan dengan nilai Critical Ratio atau CR $>2,0$. Sehingga semua indikator dapat diterima. Sedang adanya koefisien korelasi yang tinggi diantara variabel tersebut, belum tentu menunjukkan relasi kausal yang tinggi variabel tersebut. Dengan nilai $\mathrm{P}$ (Probabilitas) yang secara keseluruhan dibawah 0,05. Dengan hasil ini, maka dapat disimpulkan bahwa indikator-indikator pembentuk variabel-variabel laten telah menunjukkan unidimensionalitas. Dengan merujuk hasil analisis faktor konfirmatori ini, maka model penelitian dapat digunakan untuk menganalisis selanjutnya tanpa modifikasi atau penyesuaian-penyesuaian.

\section{PEMBAHASAN}

\section{Pengujian Hipotesis}

Pengujian hipotesis digunakan untuk menguji beberapa hipotesis penelitian seperti yang telah dirumuskan sebelumnya. Pengujian hipotesis didasarkan atas pengolahan data penelitian dengan menggunakan alat analisis SEM, dengan cara menganalisis nilai regresi seperti yang ditampilkan pada tabel sebelumnya. Pengujian hipotesis dilakukan dengan menganalisis nilai $\mathrm{CR}$ dan nilai P pada hasil oleh data Regresion Weights Full Model, dibandingkan dengan batas statistik yang disyaratkan, yaitu nilainya harus lebih besar dari 2.00 untuk nilai CR dan dibawah 0.05 untuk nilai P. Apabila hasil oleh data menunjukkan nilai yang memenuhi syarat tersebut, maka hipotesis penelitian akan dibahas secara bertahap sesuai dengan hipotesis yang diajukan pada penelitian ini. Berikut pada tabel 6 dijelaskan estimasi parameter regression weights yang merupakan hasil olah data primer.

Tabel 2 Estimasi Parameter Regression Weights

\begin{tabular}{|l|l|l|l|l|}
\hline & Estimate & S.E & C.R. & P \\
\hline MP<--- OK & 0.42 & 0.14 & 3.00 & .009 \\
\hline MP<--- KI & 0.31 & 0.10 & 3.10 & .004 \\
\hline KO<--- OK & 0.39 & 0.11 & 3.54 & .000 \\
\hline KO<--- KI & 0.47 & 0.09 & 5.22 & .000 \\
\hline OK<--- KI & 0.57 & 0.06 & 9.50 & .000 \\
\hline
\end{tabular}

Sumber: Hasil Olah Data Primer, 2016 


\section{Uji Hipotesis 1}

Hipotesis 1: Manajemen pengetahuan berpengaruh signifikan terhadap orientasi kewirausahaan. Dari tabel 2 terungkap bahwa signifikansinya ditunjukkan dengan CR sebesar 3.00 lebih besar dari 2.00 dengan nilai p sebesar 0.009 yang berarti $<0.05$. Dengan demikian H1 pada penelitian ini dapat diterima. Maknanya, dapat dijelaskan bahwa semakin baik manajemen pengetahuan yang dilakukan industri berskala kecil di Kota probolinggo ada orientasi kewirausahaan akan lebih baik. Sebuah temuan yang tentu sangat bermakna bagi manajemen, utamanya dalam rangka membangun orientasi kewirausahaan.

\section{Uji Hipotesis 2}

Hipotesis 2: Manajemen pengetahuan berpengaruh signifikan terhadap kinerja inovasi. Semakin baik implementasi tata kelola manajemen pengetahuan dilakukan, maka semakin baik kinerja inovasi ditunjukkan dengan CR sebesar 2.60 lebih besar dari 2.00 dengan nilai $\mathrm{p}$ sebesar 0,004 yang berarti $<0.05$. Dengan demikian $\mathrm{H} 2$ pada penelitian ini dapat diterima.

\section{Uji Hipotesis 3}

Hipotesis 3: Kecakapan organisasi berpengaruh signifikan terhadap orientasi kewirausahaan Dari tabel 2 tersebut terlihat bahwa pengaruh resiliensi bisnis dengan orientasi kewirausahaan ditunjukkan dengan CR sebesar 3.54 yang memenuhi syarat yaitu $>2.00$ dan nilai p sebesar 0.000 yang memenuhi syarat yaitu $<0.05$. Dengan demikian H3 pada penelitian ini dapat diterima.

\section{Uji Hipotesis 4}

Hipotesis 4: Kecakapan organisasi berpengaruh signifikan terhadap kinerja inovasi Dari tabel 2 tersebut terlihat bahwa pengaruh resiliensi bisnis dengan sustainability ditunjukkan dengan CR sebesar 5.22 yang memenuhi syarat yaitu $>2.00$ dan nilai p sebesar 0.000 yang memenuhi syarat yaitu $<0.05$. Dengan demikian $\mathrm{H} 4$ pada penelitian ini dapat diterima.

\section{Uji Hipotesis 5}

Hipotesis 5: Orientasi kewirausahaan berpengaruh signifikan terhadap kinerja inovasi Dari tabel 2 tersebut terlihat bahwa pengaruh orientasi kewirausahaan dengan kinerja inovasi ditunjukkan dengan CR sebesar 9.50 yang memenuhi syarat yaitu $>2.00$ dan nilai $\mathrm{p}$ sebesar 0.000 yang memenuhi syarat yaitu $<0.05$. Dengan demikian H5 pada penelitian ini dapat diterima.

\section{Implikasi Teoritik}

Hasil penelitian ini mendukung beberapa temuan sebelumnya diantaranya yang diungkapkan hasil riset Lisboa dan Skarmeas (2010) pada penelitiannya yang berjudul Entrepreneurial orientation, innovative capabilities, and performance outcomes: An empirical investigation, bahwa orientasi kewirausahaan memiliki pengaruh signifikat terhadap inovasi. Peneliti lain, Madhoushi, et all (2011), pada risetnya Entrepreneurial Orientation and Innovation Performance: The Mediating Role of Knowledge Management mengungkapkan bahwa orientasi kewirausahaan berpengaruh terhadap kinerja inovasi organisasi. Yang terbaru, Al-Dhaafri dan Al-Swidi (2014) pada 
artikelnya The Entrepreneurial Orientation and The organizational Performance: Does Enterprise Resource Planning Have A Mediating Role: A Study on Dubai Police menegaskan bahwa inovasi sebagai salah satu indikator kinerja organisasi berkaitan erat dengan orientasi kewirausahaan. Yang terbaru, Wang et all, (2015), pada artikelnya Entrepereneural Orientation and Organizational Learning on SME Innovation Menegaskan juga bahwa orientasi kewirausahaan berpengaruh terhadap kinerja inovasi. Keterkaitan kecakapan organisasional dengan orientasi kewirausahaan dan kinerja inovasi terungkap pada hasil beberapa periset diantaranya adalah Gholami (2015) pada artikelnya The Realtionship Between The Organizational Intelegence and The Performance of Managers menjelaskan bahwa kecakapan organisasional berpengaruh positif terhadap kinerja manajer dan salah satu indikatornya adalah inovasi. Kemudian, Ahmadi \& Ranbari, 2013) pada artikelnya Organizational Intelligence effect on entrepreneurship improvement (A case study research), menyatakan bahwa intelejensi organisasi berpengaruh signifikan terhadan orientasi kewirausahaan. Juga, Nasabee, Jahanee \& Safarpour (2013) dalam artikel risetnya Relationship of Organizational Intelligence and Personal Creativity in Shiraz University of Medical Science menyatakan terdapat hubungan searah dan signifikan antara kecakapan organisasional dengan kinerja inovasi. Bahkan dalam riset terbaru yang dilakukan Bakhsian, Hamidi \& Ezati, 2014) mengungkapkan bahwa kecakapan organisasional mempunyai pengaruh terhadap orientasi kewirausahaan. Hubungan antara manajemen pengetahuan dengan orientasi kewirausahaan dan inovasi institucional dinyatakan oleh beberapa peneliti diantaranya adalah Price, Stoica \& Boncella (2013) pada artikel hasil risetnya "The relationship between innovation, knowledge and performance infamily and non-family firms: Ananalysis of SMEs mengungkapkan bahwa terdapat hubungan antara manajemen pengetahuan dan inovasi pada industri kecil menengah. Riset lain yang dilakukan oleh Rodríguez et all (2013) yang berjudul Knowledge Management and the Effectiveness of Innovation Outcomes: The Role of Cultural Barriers mendapatkan bahwa manajemen pengetahuan berpengaruh nyata terhadap inovasi melalui variabel antara budaya.

Selanjutnya, Githii (2014) dalam artikelnya Knowledge management practices and innovation performance: a literature review mengungkapkan bahwa manajemen pengetahuan mempunyai dampak pada inovasi dalam sebuah organisasi. Kemudian fakta empiris keterkaitan transdisiplinaritas dengan orientasi kewirausahaan dan inovasi institucional dinyatakan oleh beberapa peneliti diantaranya adalah Srivasthava dan Ivanaj (2011) dalam artikelnya Transdisciplinary Art, Technology, and Management for Sustainable Enterprise mengungkapkan bahwa transdiplinaritas berdampak positip pada orientasi kewirausahaan. Juga, Gangi (2014) Arts Entrepreneurship: An Essential SubSystem of the Artist's Meta-Praxis menyatakan bahwa trandisiplinaritas mempunyai hubungan kuat dengan orientasi kewirausahaan. Mittelmark et all (2012), pada tulisan ilmiahnya Computeeer Mediated Communication in Alice Rap: Method to Enhance The Quality of Large Scale Transciplinarity Research menjelaskan bahwa trandisiplinaritas mempunyai hubungan searah dengan pencapaian kinerja inovasi. Selanjutnya, Porter (2014) dalam artikelnya $A$ Transdisciplinary Model to Improve Screening and Early Intervention within

290 BRILIANT: Jurnal Riset dan Konseptual Volume 2 Nomor 3, Agustus 2017 
Dietetics and Speech Pathology: A Case Study mengungkapkan bahwa transdisiplinaritas berpengaruh signifikan tehadap kinerja inovasi.

\section{KESIMPULAN}

Berdasarkan pembahasan hasil penelitian terungkap bahwa manajemen pengetahuan berpengaruh signifikan terhadap orientasi kewirausahaan. Juga, manajemen pengetahuan berpengaruh signifikan terhadap kinerja inovasi. Selain itu, kecakapan organisasi berpengaruh signifikan terhadap orientasi kewirausahaan. Bahkan, kecakapan organisasi juga berpengaruh signifikan terhadap kinerja inovasi. Selain itu, orientasi kewirausahaan berpengaruh signifikan terhadap kinerja inovasi.

\section{SARAN}

Temuan tersebut bermakna, terdapat keterkaitan antara variabel penelitian, namun yang menarik, orientasi kewirausahaan berpengaruh dengan koefisien terbesar terhadap kinerja inovasi. Untuk itu, penelitian lanjutan dapat difokuskan pada orientasi kewirausahaan, sehingga ditemukan indikator baru yang dapat mendokrak kinerja inovasi.

\section{DAFTAR RUJUKAN}

Abdi, K. \& Amatsewnin, A., 2015. Investigating The Impact of entrepreneurship on Organizational Innovation: Conceptual Framework. International Research Journal of Applied and Basic Sciences, 8 (6): 686-691.

Ahmadi, M \& Ranbari, M. 2013. Organizational Intelligence effect on entrepreneurship improvement (A case study research). Technical Journal of Engineering and Applied Sciences, 3 (3): 1311-1317.

Akgun, E. A., Byrne, J., \& Keskin, H. 2012. Organizational intelligence: A structuration view. Journal of Organizational Change Management, 20 (3): 272-289.

Al-Dhaafri, H. \& Abdullah Kaid Al-Swidi, A. 2014. The Entrepreneurial Orientation and The organizational Performance, Proceedings of 9th International Business and Social Science Research Conference, Novotel, ISBN: 978-1-922069-41-2

Baksian, A. Hamidi, F., \& Ezati, M. 2014. Relationship between Organizational Intelligence and Entrepreneurship among University Educational Managers. The Journal of Mathematics and Computer Science, 3(4): 413 $-421$.

Basile, A. 2015. Entrepreneurial Orientation in The Small and Medium Industries. Far East Journal of Psychology and Business, 7 (2): 1-17.

Crossan, M. M., \& Apaydin, M. 2013. A multidimensional framework of organizational innovation: A systematic review of the literature. Journal of Management Studies, 47(6): 1154-1191.

Ferdinand, A. 2013. Metode Penelitian Manajemen, Edisi Ke-4, Semarang: Badan Penerbit Universitas Dipenegoro.

Gangi, J. 2014. Arts Entrepreneurship: An Essential Sub-System of the Artist's Meta-Praxis. Journal of Arts Entrepreneurship Research, 1 (1): 19-45. 
Gholami, S. 2015. The Realtionship Between The Organizational Intelegence and The Performance of Managers. Journal of Educatioal and Instructional Studies, 2 (2): 155-165.

Githii, S.K. 2014. Knowledge management practices and innovation performance: a literature review. Journal of Business and Management (IOSR-JBM), 16 (2): 89-94.

Jian. Z. \& Wang, C. 2013. The impacts of network competence, knowledge sharing on service innovation performance: Moderating role of relationship quality. Journal of Industrial Engineering and Management, 6(1): 25-49.

Karaveg, C. 2013, Factors Affecting the Innovation Capacity of Thai Textile and Clothing Industries in Thailand. IRACST- International Journal of Research in Management \& Technology (IJRMT), 3 (1).

Khan, R.A. 2012. Knowledge Management: A Framework for Competitive Advantage. Global Journal for Information Technology and Computer Science, 1(1): 25-32.

Kocher, P-Y., Kaudela-Baum, S, \& Wolf, P. 2011. Enhancing Organizational Innovation Capability Through Systemic Action Research: ACase of a Swiss SME in the Food Industry. Syst Pract Action Research 2(4): 1744.

Lages, C. 2010. Entrepreneurial orientation, innovative capabilities, and performance outcomes: An empirical investigation. Journal of Business Research, 60 (5): 566-575.

Li, X. \& Zeng, Y. 2014. The Influential Factors of Employees' Innovative Behavior and the Management Advices. Journal of Service Science and Management, 2(7), 446-450.

Liebowitz, Jay. 2009., Building organizational intelligence knowledge Management primer. Washington. D.C.: CRC press, Bocd paton London Newyork.

Lisboa \& Skarmeas. 2010. Entrepreneurial orientation, innovative capabilities, and performance outcomes: An empirical investigation. Jurnal of Business Management, 10 (3): 35-43.

Madhoushi et all. 2011. Entrepreneurial Orientation and Innovation Performance: The Mediating Role of Knowledge Management. Asian Journal of Business Managemen,t 3(4): 310-316.

Miettinen, R., Samra-Frederics, D., \& Yanow, D. 2009. Return to Practice: An Introductory Essay. Jurnal of Organization Studies, 30 (12): 1309-1329

Pearce II, J.A., Fritz, D.A., \& Davis, P.S., 2014. Entrepreneurial Orientation and the Performance of Religious Congregations as Predicted by Rational Choice Theory. Entrepreneurship Theory and Practice.

Popadiuk, S., \& Choo, C.W., 2014. Innovation and knowledge creation: How are these concepts related. International Journal of Information Management, 26: 302-312

Price, P., Stoica, M., \& Boncella, R. 2013. The relationship between innovation, knowledge, and performance in family and non-family firms: an analysis of SMEs, Journal of Innovation and Entrepreneurship, 2 (3):14-20 
Rodríguez, at all. 2013. Knowledge Management and the Effectiveness of Innovation Outcomes: The Role of Cultural Barriers. The Electronic Journal of Knowledge Management, 11 (1): 62-71.

Settler, K.L., \& Magnusson, M. 2014. Exploring the Tension between Clarity and Ambiguity in Goal Setting for Innovation. Creativity \& Innovation Management Journal, 12 (2): 1-10.

Setyani et all. 2013. Innovation Role in Mediating the Effect of Entrepreneurship Orientation, Management Capabilities and Knowledge Sharing Toward Business Performance: Study at Batik SMEs in East Java Indonesia. Journal of Business and Management, 8 (4): 16-27.

Spin, M. (2011). The effect of intra-organizational routines and interorganizational routines on collaborative innovation performance. An experiment. (Master's thesis). Universiteit Twente, Enschede.

Sugito, P. \& Kamaludin. 2017. Keterkaitan Transdisiplinaritas dengan Keunggulan Bersaing Serta Fungsi Mediasi Adaptabilitas Organisasi. Buletin Studi Ekonomi, 22 (1): 43-52.

Temmel, S., Metion, A., \& Torkolie, M. 2013. The Impact of Cooperation on Firms' Innovation Propensity in Emerging Economies. Journal of Technol Management Innovation, 8 (1): 54-64.

Ullah, $\mathrm{H}$ et all. 2016. Enterprise related factors influencing entrepreneurial orientation: Evidence from Khyber Pakhtunkhwa Province of Pakistan. African Journal of Business Management, 7 (39): 4096-4108.

Wang et all. 2015. Entrepereneural Orientation and Organizational Learning on SME Innovation. International Journal of Oranizational Inovation, 7 (3): 65-75.

Yaqoubi, N \& Narroui, M. 2016. Affecting Factors on Entrepreneurial Orientation in the Industry. Journal of Chinese Business Review, 10 (10): 889-894.

Zang, J., \& Cheng, L. 2014. The Review of SMEs Open Innovation Performance. American Journal of Industrial and Business Management, 5 (4): 716720.

Zaied, A.N.H., Hussein, G.S., \& Hassan, M.M. 2016. The Role of Knowledge Management in Enhancing Organizational Performance. International Journal Information Engineering and Electronic Business, 5: 27-35. 